\title{
REGIONAL AMBASSADORS - AN INNOVATIVE ELEMENT FOR THE DEVELOPMENT OF RURAL AREAS?
}

\author{
Jörn Harfst, Patrick Pichler, Wolfgang Fischer ${ }^{1}$
}

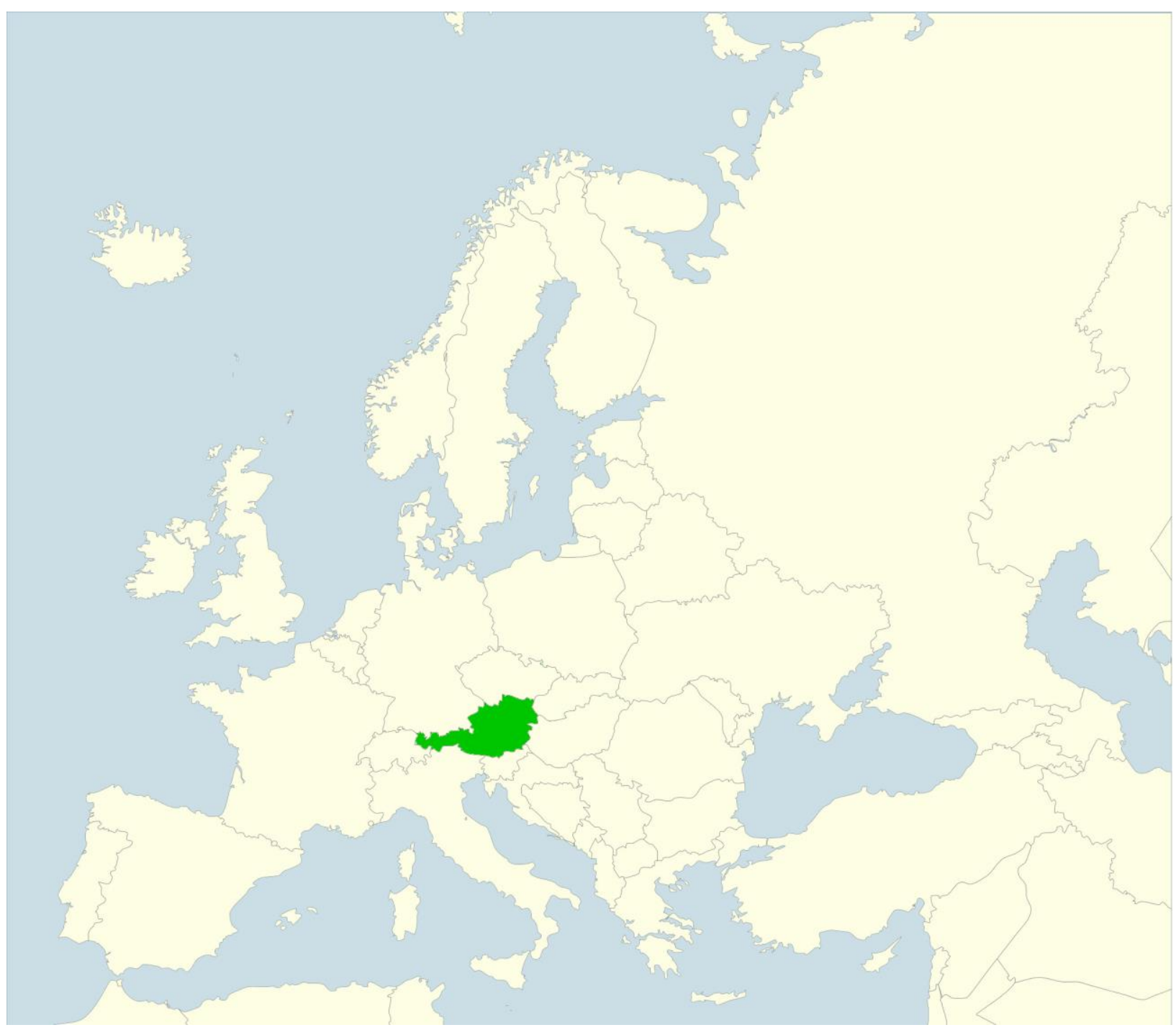

1 Dipl.-Geogr. Jörn Harfst, Patrick Pichler, Mag. Phil. Dr.rer.nat. Wolfgang Fischer, Department of Geography and Regional Sciences, University of Graz, Heinrichstraße 36, A-8010 Graz, Austria; wolfgang.fischer@uni-graz.at; j.harfst@uni-graz.at 
Abstract: Rural regions in Austria have been under increasing pressure for change in the last decades. On a regional level, varying development patterns of shrinkage and growth arise alongside economic, demographic and social parameters. In this paper, regional ambassador concepts will be explicated as a new instrument of regional development. Additionally, potential positive impacts of these approaches on the problems faced by rural, structurally weak regions will be highlighted. Notable advantages of these approaches are network and feedback effects between stakeholders. These, in turn, are capable of improving the economic and social situation in those regions. However, these measures require a high degree of control capacities which structurally weak areas often lack.

Keywords: Regional development, regional ambassadors, regional networks, governance, structural change

Abstract: Kleinstädtisch-geprägte Regionen Österreichs stehen in den letzten Jahrzehnten unter verstärktem Veränderungsdruck, wobei sich regional unterschiedliche Entwicklungsmuster von Schrumpfung und Wachstum entlang ökonomischer, demographischer und sozialer Faktoren ergeben. In diesem Text werden regionale Botschafteransätze als ein neues Instrument der Regionalentwicklung dargestellt, welche positive Einflüsse auf die Problemstellungen von kleinstädtisch-geprägten, eher strukturschwachen Regionen haben können. Vorteile sind vor allem die dabei entstehenden Netzwerk- und Feedback-Effekte zwischen Akteuren, welche die wirtschaftliche und soziale Situation in solchen Regionen verbessern können. Allerdings erfordern diese Maßnahmen ein hohes Maß an Steuerungskapazitäten, welche gerade in strukturschwachen Räumen oft fehlen.

Schlüsselwörter: Regionalentwicklung, Regionale Botschafter, Regionale Netzwerke, Governance, Strukturwandel

\section{Introduction}

The settlement pattern of Austria - as in many other Central European countries - is characterised by a multitude of rural regions, marked predominantly by small towns. These structures are diverse and shaped by versatile spatial processes (social, demographic, economic) which lead to distinct developmental patterns. In terms of small towns, these processes often result in new challenges, especially in conjunction with the economic change of structures and functions. At the same time, peripheral and structurally weak areas are confronted with problematic demographic developments that are, to some extent, accompanied by a rapid loss of functions. In recent decades, elements of urban and regional development have carried out increasingly self-reliant by regions, cities and municipalities in Austria. In rural areas, especially the administrative structure of LEADER-funding has been beneficial in this respect. This trend applies both to the professionalization of urban and rural development, as well as to the field of modern regional marketing. Today, regional marketing presents itself as a cross-sectional task between spatial development, location policies and public relations (Grabow et al., 2006; Mathis, 2013). According to Lechner (2014), both cases are a matter of "concepts and measures which support the economic development of a region". It aims at a region's positioning in the perceived competition for potentials of growth, such as population, jobs and enterprises (Helbrecht 1994; Jannich, 2009).

A relatively new element within the domain of these regional marketing strategies is the initiation and utilisation of so-called ambassador approaches. They stand in line with a range of new alternative approaches, which regions and cities have used in the recent past, focussing on "soft" locational factors. Moreover, the increasing significance of regional stakeholders and personages in terms of location marketing can be observed. Because of the comparatively low 
capital costs, ambassador approaches are considered to be exceptionally effective. Thereby, this approach is regarded as a sound and reasonable marketing instrument for the enhancement of the competitiveness of structurally weak regions (Andersson \& Ekman, 2009a; Silvermann, 2011).

By reference to an Austrian case study, this paper illustrates how predominantly small town regions practically implement ambassador approaches in the field of regional development. The quintessence of this analysis is the question, what possibilities and difficulties arise from the implementation of such initiatives in peripheral and structurally weak regions. Ultimately, the paper at hand assesses whether such approaches constitute an innovative and successful way to regional development in these areas and what preconditions must be fulfilled.

The basis for this examination is the research carried out by the authors within the EUINTERREG project SHIFT-X (2012-2014, Central Europe) which dealt with the valorisation of regional potentials in peripheral old industrial regions (www.shiftx.eu). In the course of this project, a survey on the potential utilisation of ambassador approaches in the case study region was compiled (Steirische Eisenstrasse 2014) and an in-depth master's thesis related to this topic was prepared (Pichler, 2015).

This article is divided into 6 sections: Following the introduction, section two provides a first insight into the problems faced by rural, predominantly small town areas in Austria and discusses the general character of ambassador approaches. This is necessary because the ambassador instrument has so far been only examined within a very limited body of work within the regional development literature. Section three integrates the ambassador approaches into the development of rural areas, amongst others by illustrating two brief case studies from Central Europe. Subsequently, section 4 is composed of an in-depth analysis of the ambassador approach utilised by the Steirische Eisenstrasse in Austria. Section 5 includes a discussion of the case studies by taking up the characterisation described in the previous parts. The $6^{\text {th }}$ and final section consists of a conclusion highlighting the opportunities and threats of ambassador approaches within the field of regional development, with a special focus on small cities located in peripheral and structurally weak regions.

\section{Theoretical background}

\subsection{Situation of small town regions in Austria}

As in other Central European countries, small towns are an important part of the Austrian settlement system. As already highlighted in other contexts (for an European discussion see a.o. van Leeuwen, 2010; Kwiatek-Soltys et al., 2014) these places often fulfil important functions, serving as centres of rural areas, thus providing jobs, services and fostering social contact and regional identities (Courtney and Errington, 2000; Vaishar and Zapletalová, 2009; Servillo, 2014). The character of small towns is also marked by a high diversity, differing according to their historic development, economic structures and social strata of their inhabitants. Additionally, their geographic position, i.e., in suburban context or peripheral regions, often determines development opportunities, attractiveness and infrastructure provisions (Knox and Mayer, 2013). Some researchers point to the increased development challenges faced especially by more peripheral, structurally weaker places (Collits, 2008; Erickcek and McKinney, 2006).

All these characters can also be found in the Austrian context, a country marked by predominantly rural landscapes and only few metropolitan agglomerations, albeit with strong suburbanisation tendencies (Österreichischen Raumordnungskonferenz (ÖROK), 2009). Perhaps because of the diverse pattern, the Austrian planning system lacks a coherent definition of small towns. In the context of this text, we follow Bähr (2011), defining small towns as places with 5,000 to around 20,000 inhabitants. Trends towards an increased centreperiphery drift in Austria have been fostered in the past two decades by the opening of Eastern European borders and accelerated integration into the European market. This resulted in heightened competition between regions and towns for jobs and investment, generally strengthening centralised locations, a process which is 'eroding' traditional settlement patterns 
(Giffinger and Kramar, 2008). Processes of regional growth and shrinkage - along economic, demographic and social indicators - now form a fragmented pattern with different combinations across the country (Giffinger and Kramar, 2008, 2012).

These trends are also mirrored by the Austrian spatial development and planning system. Spatial planning now follows a functional approach, identifying 38 city regions and agglomerations, which form the central arenas of governance and planning within the spatial system (Österreichischen Raumordnungskonferenz (ÖROK), 2009). These city regions combine densely populated areas with their functional hinterland. Mirroring intervention and funding elements on European level (i.e. LEADER), the Austrian strategic outset favours functional units as a major area of coordination and cooperation. From a development point of view, small towns are therefore only valid in connection to the bigger macro-regions in which they are integrated in. This gives, on the one hand, side the possibility for a greater cooperation and coordination of functional entities, but on the other hand, holds no specific leverage for the specific development needs of small towns, especially in peripheral regions (Österreichischen Raumordnungskonferenz (ÖROK), 2015).

This text will explore one aspect of the new cooperation structures in the Austrian city-regions with specific focus on small towns. The geographic focus will be on an old industrial region in Upper Styria, marked as structurally weak and peripheral, thereby characterising the 'losers' of the above marked types of small towns. The text will explore new elements and innovative formats of regional cooperation and their opportunities and risks for the development of such regions dominated by small towns. One of these new elements is the regional ambassador model, which will be introduced in the next chapter.

\subsection{Ambassador concepts as an instrument in regional development}

The implementation of brand ambassadors is a relatively novel phenomenon but one which is gradually becoming more established as a practice in location marketing and development (Andersson and Ekman, 2009a). Such novel elements of regional marketing might be a reaction to new forms of consumption, such as eco-volunteering, scientific tourism, adventure tourism, and spiritual tourism (Moinat and Diesbach, 2009). Therefore, in addition to conventional means of regional marketing, approaches, which highlight "soft" location factors, can now be observed more frequently. Local specifics, such as regional specialities in gastronomy but also outstanding natural features can play a decisive role in this respect (Go and Govers, 2010; Baker, 2012; Rehmet and Dinnie, 2013). In the same line of action fall approaches which capitalise on regional personalities. The main objective in this context is to address certain target groups directly and personally in order to convince them of a location.

Although these approaches are still considered to be an emerging element of regional marketing, ambassador concepts have seen growing dissemination over the past few years. One reason for this is new communication patterns which have been revolutionising traditional forms of location marketing - most notably in the light of online-marketing (Dinnie, 2011). This development accentuates the significance of communication via personal networks instead of focusing on conventional methods of location marketing such as printed media or billboard advertisements (Ashworth and Kavaratzis, 2007; Govers and Go, 2009). This kind of ambassador marketing is held to be particularly effective since it operates via networks which render it more credible than conventional campaigns (Silverman, 2011). Moreover, this effect can be achieved through comparatively low capital costs which, in turn, appeals to a range of municipalities and regions.

Ambassador approaches have spread from Northern to Central Europe in recent years. These schemes are applied in metropolitan areas (e.g. "Hamburg Ambassadors", "beBerlin") as well as in rural regions (see Chapter 3 ) in order to raise the awareness among different target groups with regard to the benefits of the area (see Fig. 1 and 2). 

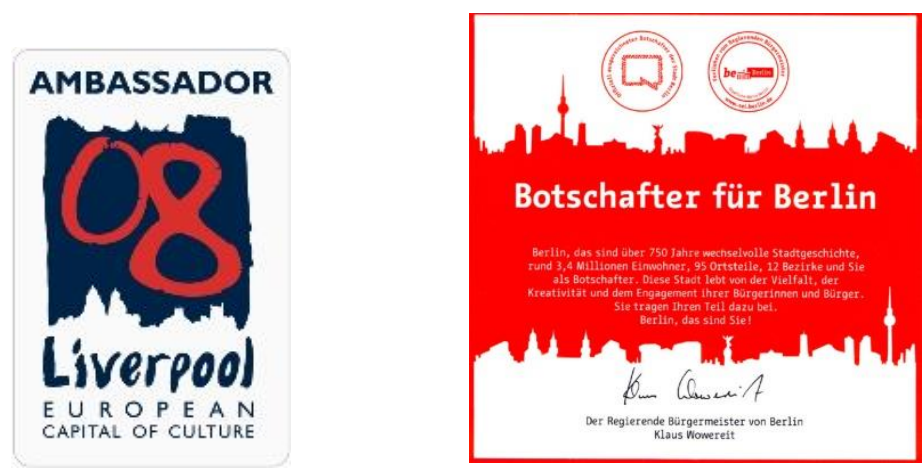

Fig 1, 2. Promotion of ambassadors in Liverpool (2008) and Berlin (2012).

Previous research has emphasised the two-fold impact of ambassador approaches: On the one hand, ambassadors can strengthen the image of a location on various levels outside of the municipality or region and/or consolidate the civil commitment within these entities. On the other hand, the competitiveness and the ability to solve problems are implicitly strengthened if internal processes between the participants unfold. The aspect of communication particularly plays a crucial role in the first phase of such networks and is the result of new contacts, an enhanced image and an overall increased attention for the municipality or region. The second aspect can be located in more ambitious approaches: new ideas, expertise and creativity generated by the network are continuously developed which, in turn, are capable of contributing to regional development (Andersson and Ekman, 2009). This contribution will mainly focus on the second, regional development-related impact of these networks.

\subsection{Definitions and characteristics}

An ambassador-network is defined as a network whose primary goal is to merchandise the image and attractiveness of a site. The network consists of people with real or perceived connections to a location. Another criterion is the planned or wilful initiation of such an intention. An ambassador can be recognised by the coordinators of the network, for example, as being a credible opinion leader of the character and attractiveness of a location. By making use of word-of-mouth marketing for example, these ambassadors are capable of influencing others through their networks and contacts. Owing to their occupational and social role, the ambassadors can gain access to new target groups for the region (Andersson and Ekman, $2009 \mathrm{~b}$, p. 42). Depending on the kind of network and its goals, also other types of ambassador and tasks are also possible - different approaches are disscussed in the case studies in section 3.2 and 4.

Various natures of networking types can be employed, depending on the objective and the respective target group. In this regard, wholly different stakeholder motivations as well as organizational forms - depending on the nature of the network - can play a role (Andersson \& Ekman, 2009b; Pichler, 2015).

Andersson, Ekman and Solitander (2012) highlight the benefits in the use of ambassador networks as follows:

- Ambassador networks can - in conjunction with the region - constitute effective instruments of marketing and regional development

- Ambassador networks can be valuable for the response / adaptation to changes. The members of the network act as communication channels and inform about the most important developments in and around the region. Furthermore, they can be a vital source of know-how, expertise and creativity

- Ambassador networks are pivotal tools of brand development because they perform both the marketing communication, as well as increasing the attractiveness of municipalities or regions. 


\section{Ambassador concepts in structurally weak, small town regions}

The main focus of this paper is on structurally weak, small town regions and how ambassadors can, by using various marketing elements, contribute to successful regional development. The following section exemplifies how the described benefits are of particular interest by illustrating two examples for current use of different forms of ambassador concepts in small towns.

\subsection{Structurally weak, small town regions in Austria}

A general, consistent definition of structurally weak, peripheral municipalities is difficult, also in the Austrian context, due to the concurrence of many diverse factors. The Austrian Spatial Development Perspective (ÖROK, 2002, p. 16) for instance, identifies structurally weak areas as sites where occupational opportunities, accommodation, cultural institutions and social infrastructures exist merely in marginal quantities and/or at a low diversity. In doing so, different economic, demographic and social indicators ${ }^{2}$ are synthesised in order to form five types of rural spaces:

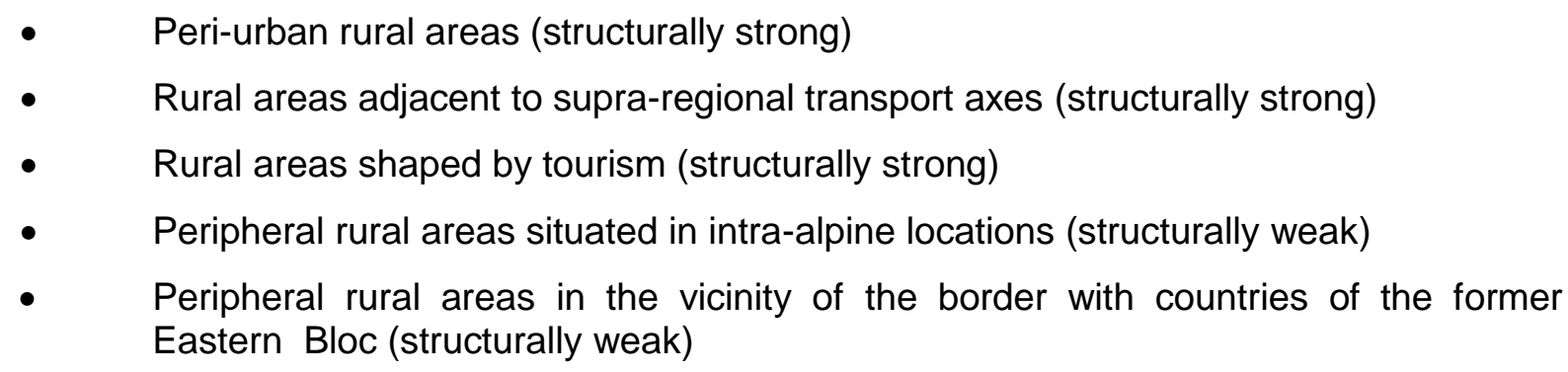

The map deduced from these indicators (Fig. 3) illustrates the complexity of the Austrian settlement development in non-metropolitan areas. However, the subdivision of the regions has to be understood as ideal types, whereas the development pattern in reality is by far more complex. Nevertheless, it becomes apparent that structurally weak areas are predominantly marked by small towns and are rural-based.

Facing the erosion processes in the settlement development as described in section two, the intervention logic in the Austrian rural areas has also changed in recent decades. The focus of regional development activities is placed on (functional) regions, a circumstance which is also underpinned by numerous national and European development programmes (e.g., LEADER), strategies and measures. On the contrary, the leeway of single (small) towns and municipalities has been perceptibly restricted in the course of the last decades.

Such regional development programmes aim now mostly at the utilization of synergetic effects amongst regional stakeholders, which is also still highlighted by the Austrian spatial planning body (Österreichische Raumordnungskonferenz (ÖROK), 2015). Therefore, ambassador concepts could be well suited for such contexts since they are geared directly towards the establishment of regional networks. For peripheral regions, the potential of creating communication tools is of particular interest. With the help of these tools, supra-regional attention could be generated by circulating and propagating diverse content matter. The huge advantage of ambassador networks - their excellent cost-benefit ratio - renders them interesting for many municipalities and regions. In comparison to conventional marketing campaigns, the expenses are primarily limited to personnel costs necessary for mentoring the network and to accompanying marketing actions. Consequently, this instrument is interesting for peripheral and structurally weak areas, as endogenous resources can be mobilised inexpensively in order to generate an array of potential benefits related to regional development.

\footnotetext{
2 Demographic development, employment rate of women, development of the employment figures, share of employees in agriculture and forestry, share of daily commuters, share of persons not commuting on a daily basis, intensity of overnight stays, tax revenue per capita (ÖROK, 2002).
} 


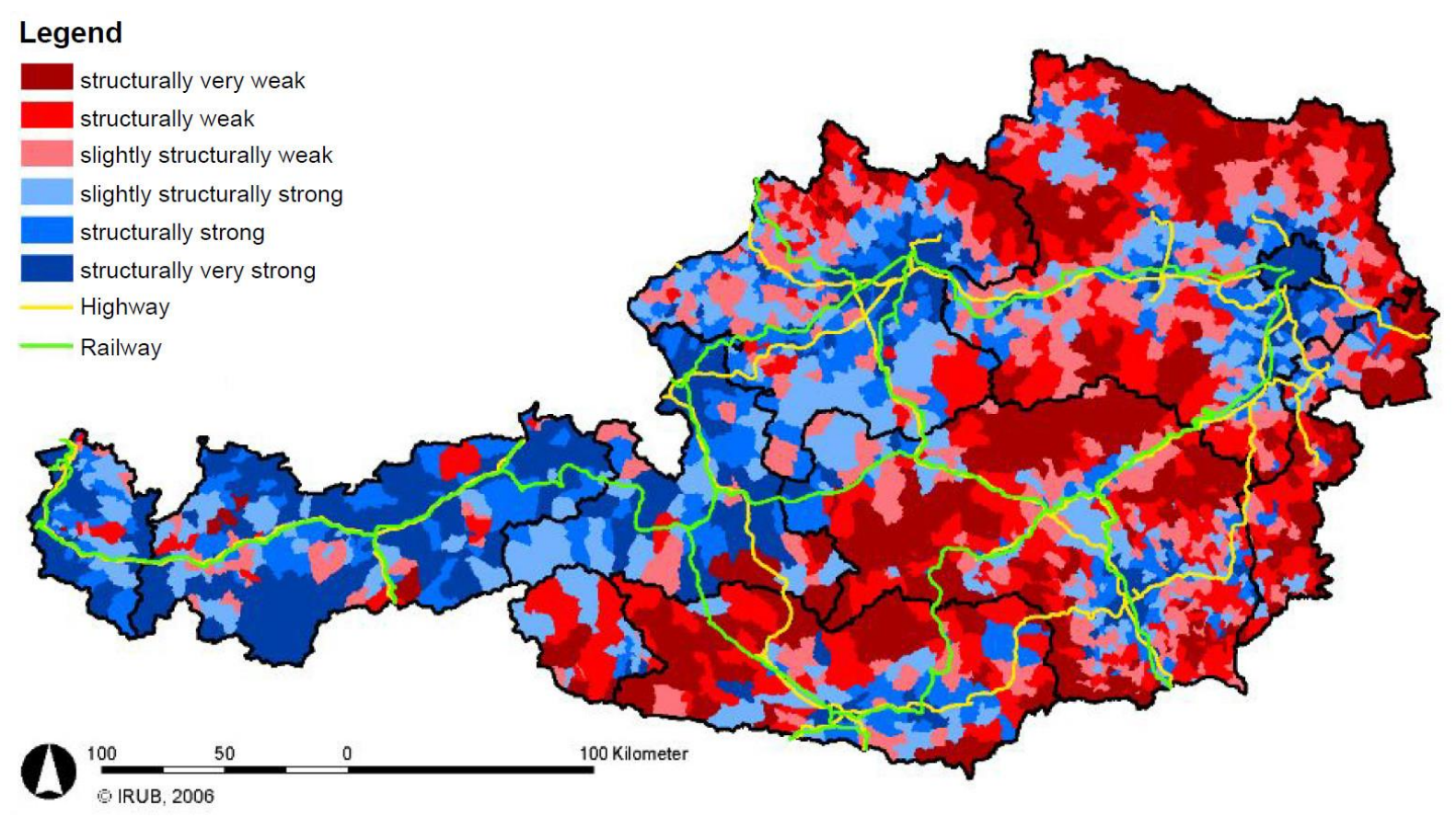

Fig 3. Settlement Development of Austria.

In the following sections, the present paper illustrates several case studies concerning ambassador concepts as well as the opportunities and threats that arise in the realisation thereof. The objective is to develop a better understanding of such approaches as an innovative element within the regional development of structurally weak and peripheral areas. Concerning small towns in peripheral locations, the text at hand raises the question how such instruments could be put into practice, what effects could be attained and how the particular problems of small towns could be incorporated into these approaches. Before discussing more closely the example of municipalities located alongside the Steirische Eisenstrasse more closely, two brief case studies are presented in the following section in order to enhance the understanding of the issue's complexity. In section 4, the case study "Steirische Eisenstrasse" is examined at full length.

\subsection{General case studies}

In Central Europe, several examples of ambassador approaches in peripheral and rural areas can be found. They have been put into practice in various regions, amongst others in Oberlausitz (Germany), Lower Bavaria (Germany), Fichtelgebirge (Germany) and the district of Murau (Austria). Below, two different ambassador approaches are briefly described and their fields of application illustrated.

\subsection{1 "Wohnen im Waldviertel" ("Living in the Waldviertel")}

The Austrian Waldviertel is a structurally weak, rural region located in the federal state of Lower Austria. The largest city of the region is Krems an der Donau with approximately 25,000 inhabitants. The entire region's other towns are considerably smaller than Krems. Altogether, the total population accounts for roughly 220,000 residents (Statistik Austria, 2015). The area is particularly shaped by its proximity to the metropolitan region of Vienna.

The Waldviertel ambassador concept has existed since 2009 and was elaborated as part of the regional strategy "Waldviertel 2015+". The strategy has been overseen externally by a private regional development company since 2010. In the case of Waldviertel, the region's "ordinary" residents are explicitly addressed. There is no pre-selection of ambassadors, which means anybody can become a Waldviertel ambassador and, thereby, demonstrate his/her connection to the region. The main duty of the ambassador is to carry further the region's strengths and report on the quality of living in the Waldviertel region first-hand. In 2014, the project recorded a peak in ambassadors ( 420) and participating municipalities (56), 
compared to merely 140 ambassadors in 2011. Each ambassador has different functions, depending on the various aims, such as participating in meetings, communicate with target groups and represent the region and their values. The ambassadors of Waldviertel are mainly used for convincing other people of relocating by pointing out (in 2-3 sentences) their perceived advantages of living there.

The Waldviertel ambassador project is one of the largest voluntary municipal co-operations in Austria. The recognition of the importance of principal residences as a municipal source of income and the analysis of real estate prices has prompted the organisers to focus on the issue of "living" as the project's primary topic. Due to the location of the region near the conurbations of Vienna and Linz, the project is able to solicit to a large target group. Means of marketing are an internet platform in which statements of the ambassadors on the region are collected as well as an ambassador gathering that takes place annually and allows for the participants to exchange experiences and knowledge.

This approach particularly focuses on addressing the ambassadors authentically and personally (Fig. 4). The main objective is not the promotion of the business location but rather to position the region as an attractive place worth living in. At the same time, the ambassadors are but one element of an entire package of measures ("municipal guides", platform for the regional job market, real estates and services). The measures aim at enhancing the attractiveness of a peripheral region in Lower Austria to newcomers.

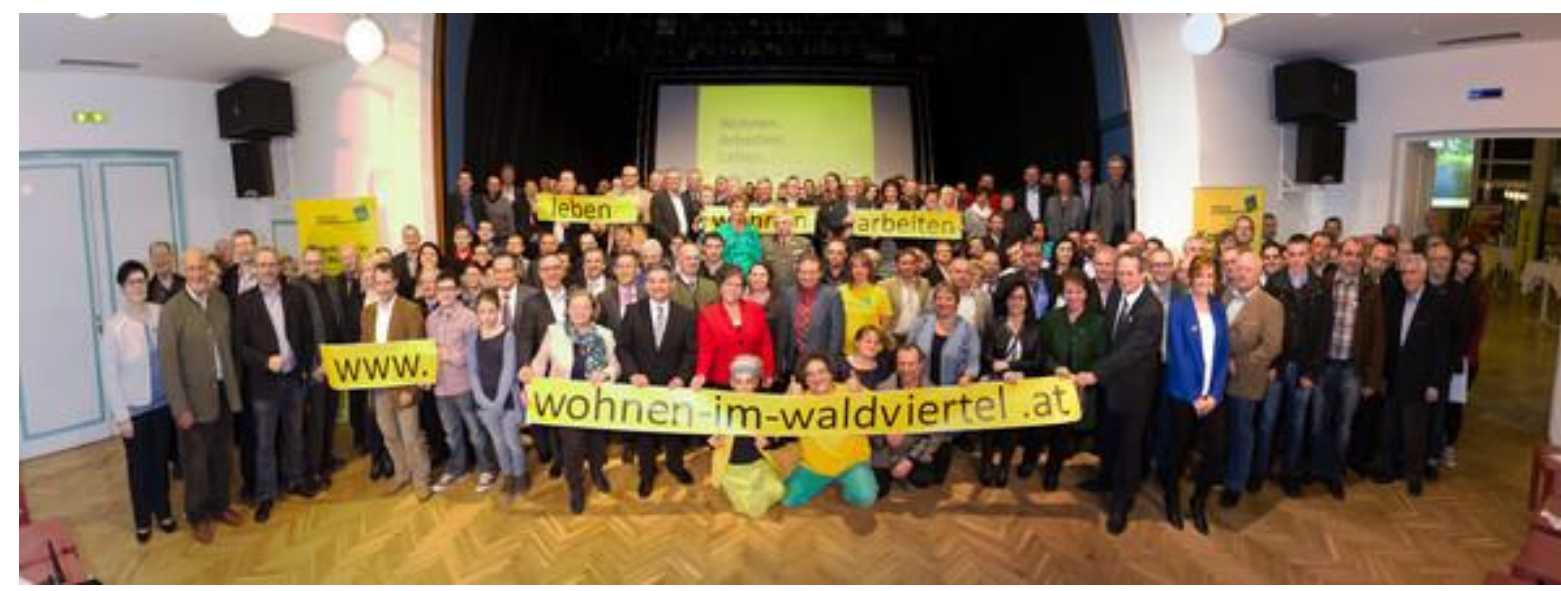

Fig 4. Waldviertel ambassadors (www.wohnen-im-waldviertel.at).

\subsection{2 "Erzgebirgs-Botschafter" (Erzgebirge Ambassadors)}

The Erzgebirge is a peripheral, rural region located in Eastern Germany, in immediate proximity to the Czech Republic. The region is dominated by a multitude of small towns with up to 20,000 inhabitants. Annaberg-Buchholz (ca. 20,000 residents) is the region's largest city. In total, 350,000 people live within the borders of the administrative district (Statistik Sachsen, 2015).

The ambassador approach implemented in the Erzgebirge district was established on the initiative of the regional management board in 2010. In 2015, 100 persons hailing from the fields of economy, politics, culture and sports already represented the district to the outside. The superordinate goal of the marketing campaign is to publicise Erzgebirge's full scope of diversity and its accomplishments. Both the region's touristic and economic aspects play an important role in this respect. The campaign was marketed offensively from the very beginning, amongst others with the help of the regional edition of a large German tabloid. Advertisement campaigns depicting ambassadors from the field of economy as a special marketing element. By making use of these advertisement campaigns, the accomplishments of the ambassadors' enterprises are portrayed in order to represent the region (Fig. 5).

This reflects the ambassador approach's strong orientation towards stakeholders from local economy. The most important collective event is the annual ambassador meeting. At this event, 
the ambassadors as well as representatives of the administrative district meet at the site of a regional company. There, the ambassadors are invited to share their experiences. These meetings are also used to continuously extend the set of persons whose supra-regional fame can contribute to the campaign. At these meetings, the District Administrator appoints new Erzgebirge ambassadors.

The objective of this approach focuses strongly on the business community, a circumstance which is reflected in the advertisement campaigns. On the other hand, famous athletes can also be found amongst the ambassadors.

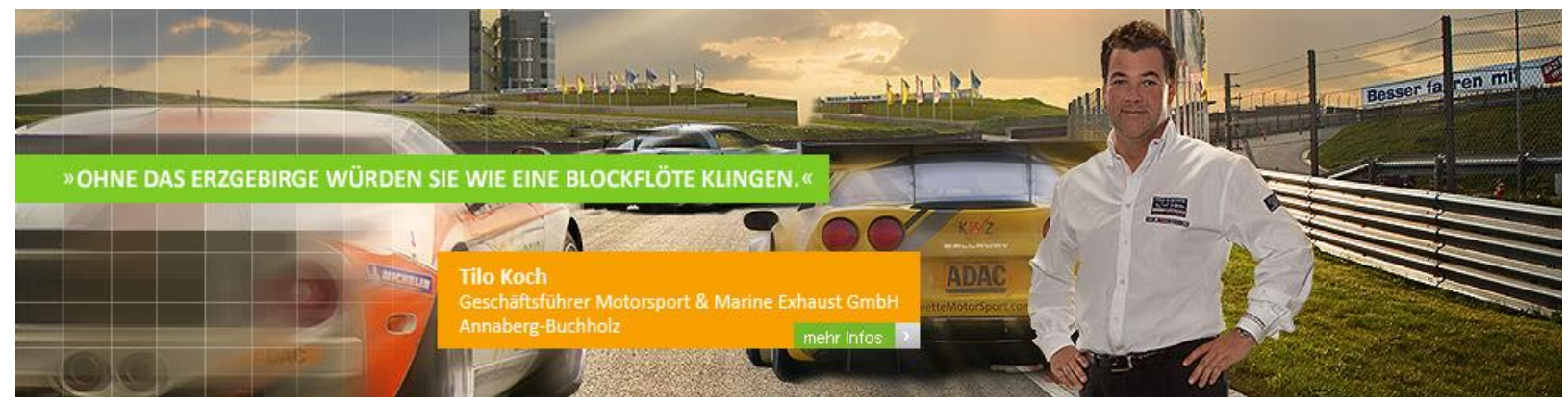

Fig 5. Marketing of the Erzgebirge ambassadors (www.wirtschaft-im-erzgebirge.de).

\section{Case study Steirische Eisenstrasse}

As part of the EU-INTERREG project SHIFT-X (2012-2014, Central Europe), the association "Steirische Eisenstrasse" conducted a PR-campaign highlighting industrial heritage. This campaign was based on an ambassador concept. The corresponding activities were scientifically supervised by the Department of Geography and Regional Science of the University of Graz (Steirische Eisenstrasse 2014). In addition, a master's thesis on regional ambassador concepts was compiled in the course of this project (Pichler, 2015). This paper's empirical elements are based on research on European data and case studies, SWOTanalyses, in-depth interviews with regional stakeholders as well as focus group interviews. The objective of the analysis was to examine the elements of an ambassador concept in the case of "Steirische Eisenstrasse" and to propose actions with regard to potential target groups.

Steirische Eisenstrasse is the name of a regional association (Verein Steirische Eisenstrasse e. V.) as well as the designation of one of the official LEADER regions in the state of Styria, Austria. Despite the fact that the two organizations do not have exactly the same spatial extent, they both cover parts of the former heavy industry and mining area in the north-east of Styria (Mur-Mürz-Furche). While the northern, alpine section, with its centre Eisenerz, is relatively difficult to access, the Upper Styrian metropolitan region is adequately connected to transport infrastructures and to Styria's state capital Graz. The regional centre and provincial capital of Leoben (2014: 24,466 inhabitants) is located within the Steirische Eisenstrasse area and is well equipped with infrastructure facilities. The region's cities and villages are significantly smaller (Lichtenberger 1997; Zimmermann/ Janschitz 2004).

The region has a century-long history of mining and iron processing. With industrialisation in the mid-19 $9^{\text {th }}$ century, the region developed into a national centre of iron ore mining (Erzberg) and iron processing (Leoben-Donawitz). The golden age of the region's industry was during both World Wars and the 1970s (Sperl 1984; Osebik 2012). The relevance of the iron manufacturing industry, however, began to decline in the 1960s due to developments on the world market (Lichtenberger 1997). In 2010, about 200 people were still employed at the Erzberg mining site with an annual output of ca. two million metric tons of iron ore. The VOEST Alpine steel mill located in Leoben-Donawitz employed around 1,300 people in 2012. The employment data of 2006 reveal that the region's portion of jobs in the manufacturing sector was still above the national average, although significantly reduced compared to 1981 $(49.9 \% 1981 ; 31.8 \% 2006)$. One of the biggest problems nevertheless is the demographic 
development: the population numbers of the entire region has decreased drastically over the last decades (District of Leoben 1981-2012: -32\%). Especially the northern section, around Eisenerz, was affected heavily by this development (Municipality of Eisenerz 1981-2016: $-57.4 \%$ ) (Osebik 2012; Fischer et. al. 2016).

\section{City region and permanent settlement area according to ÖROK (2009)}

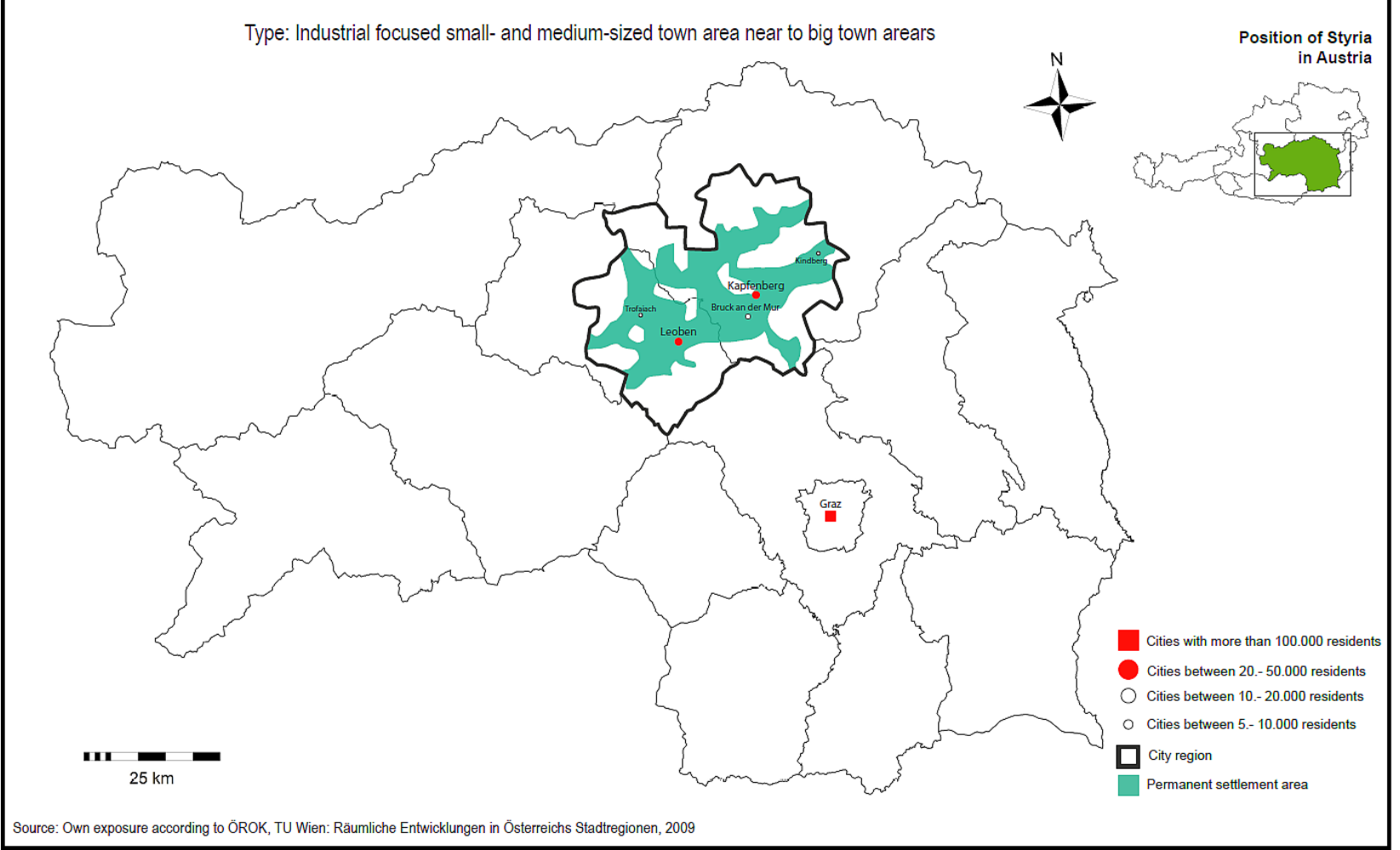

Fig 6. Area of the Steirische Eisenstrasse.

\subsection{Introduction to the region}

Mining plays an important role in the region's development strategy. This is related to the circumstance that mining generally has a positive connotation in the area and many local traditions are connected to it. Due to that, mining constitutes an integral part of the region's tourism strategy. The LEADER development strategies (2007-2013 and 2014-2020) both designate different top priorities for the region: While the high-tech-industries should still play an important role in the regions traditional centres (Erzberg area and Leoben), the tourism related activities should be increased, particularly outside of the centres. All in all, the region is a challenging tourism destination: The industrial image, a lack of services and investments related to tourism constrain its development. At the same time, the competition on the domestic tourism market is strong (Pizzera/Osebik 2012; Harfst and Wirth, 2014).

\subsection{Present ambassador approach}

The official ambassador approach of the Steirische Eisenstrasse was initiated in 2013 with the appointment of Gerhard Koch, chief editor of the Austrian Broadcasting Corporation (ORF), as Eisenstrasse's first ambassador. In the following years political representatives Kurt Wallner (mayor of the city of Leoben) and Michael Schickhofer (Deputy state governor), also became ambassador for the region. The association "Steirische Eisenstrasse" appoints the ambassadors as part of a feast dedicated to Saint Barbara, a ceremony which is attended by many stakeholders from the region. In addition to these three representatives, 17 'honorary miners' have been appointed, which have received this distinction due to previous activities for the region. The representatives also come from local politics or economy, but cannot be denoted as ambassadors in the conventional sense because only their past activities were 
honoured and no precisely defined future tasks were agreed upon (Verein Steirische Eisenstrasse, 2014i).

The development of the 'honorary' miner's title into an actual ambassador approach is based on the idea of a more structured and guided involvement of certain stakeholders for regional tasks. The objective is to present the regional heritage (e.g., the scenic uniqueness, the strengths of the region's modern industries as well as cultural highlights) to the public with the help of ambassadors. This is seen as necessary as in the outside view on the region; an image of heavy industry and outmigration is prevailing. The target group of this approach are stakeholders from outside the Eisenstrasse region as well as local stakeholders and residents. Chief editor Gerhard Koch defines the contact to people from both inside and outside the Eisenstrasse region as one of his principal tasks as the ambassador (Verein Steirische Eisenstrasse, 2014 h, p. 4). He points out that there is "a huge discrepancy between the region's internal and external perception [...], which needs to be counterbalanced". The authenticity and the relation of the ambassadors to the region could help contribute to the structural change of small towns. "Before becoming a crisis region, the Steirische Eisenstrasse region and the MurMürz-Furche respectively were themselves the lifeline of Styria for a long time" (Koch, 2014).

The Verein Steirische Eisenstrasse (2014f, S. 33-34) formulates preconditions that must be fulfilled for the appointment of ambassadors:

- Strong and sincere relation to the region (identification). It is not compulsory to have one's place of residence in the region.

- Well-established connection to industry, media or politics as well as possessing a respective network, particularly outside of the region (Styria, National, International).

- Strong personality and corresponding curriculum vitae that is adequate for presenting oneself as an ambassador.

- Willingness to actively contribute to the development and marketing of the region.

The duties of the chosen ambassadors are predominantly affiliated with the aforementioned demand profile. Until now, media coverage amounted to reports on the appointment of the first ambassador by the ORF-programme "Steiermark heute" as well as a new regional image brochure ("Steirische Eisenstrasse - Cradle of iron and steel"). It serves as a basis for the ambassadors but also for other regional stakeholders such as municipalities and industrial companies.

\subsection{Objectives of the expansion and prospects}

Since its introduction, the ambassador approach has been subject to a constant discussion in the region - a process that has not reached a conclusion yet, despite the approach featuring in the new LEADER strategy 2014-2020, which highlights the following key points regarding the future of the project (Verein Steirische Eisenstrasse, 2014h, p. 11ff):

- Appointment of two ambassadors per year.

- Ambassadors for young people as an additional element. Ambassadors from the fields of sports and culture can act as positive role models. The region has brought forth a multitude of world champions and winter sports athletes.

- In the future, the appointment ceremonies should focus on the ambassadors. The annually hosted event should generate regional attention and, at the same time, communicate important news from the region.

- Involvement of the entire region: The location of the appointment ceremony should alternate between municipalities every year. This should enhance the identification of the population of all municipalities with the ambassadors. 
- Starting with 2015, ambassador meetings between ambassadors of the Eisenstrasse and honorary miners should take place in order to interlink the ambassadors with each other.

The key points mentioned above primarily aim at enhancing the involvement of the target groups and the overall population. The annually alternating venues of the appointment ceremonies point towards decentralization and the corresponding involvement of stakeholders from the entire region.

As pointed out, the discussion process in the region with regard to the future organization of the ambassador approach is still on-going, therefore a final evaluation of the approach is hard to make at the current moment. While the new ambassador concept itself shows a clear upgrade to the previous model of 'honorary miners', i.e. by highlighting explicit target groups and instruments, the realisation of these elements has been very slow. New ambassadors in 2015 and 2016 were chosen from the political field only and the yearly meeting of the ambassadors has not happened yet. Especially the resource-input and administrative costs were subject to particular considerations and discussions within the region. With the new LEADER strategy 2014-2020 adopted, it will need further efforts to practically underlay the strategic aims and focal points with practical measures and the allocation of necessary resources.

\section{Discussion}

Based on the three case studies described in the previous chapters, a couple of opportunities and challenges concerning the implementation of ambassador approaches in small towns from peripheral and structurally weak regions can be discussed.

First of all, it can be observed that in none of the aforementioned examples a single municipality or small town alone has initiated an ambassador network. Co-operations on a regional level (though in varying sizes) are prevalent - which is also reflected in the area addressed by the schemes (e.g. administrative district, LEADER region). While single towns or municipalities are indeed able to provide important functions within the network, on the whole, it is primarily a joint accomplishment. These joint efforts are coordinated by institutions which are in any case concerned with regional development issues (e.g., regional management, district administration, LEADER action group).

Moreover, the examples clearly show that most regions make use of recurring methodological approaches (e.g. ambassador meetings, marketing elements). These, however, vary with regard to the objective and the target groups. The Erzgebirge example can be described as a business-oriented approach. The central aim of this scheme is to create a "decider"-network within the region which is oriented towards economic interests and primarily focuses on the economic strengths of the region. In contrast, the Waldviertel model has an entirely different goal. By making use of the residents themselves the solidarity of the local population should be fostered and the location's qualities of life communicated outwards. The defined target groups are the residents themselves as well as potential newcomers. The Steirische Eisenstrasse approach with its honorary miners and new Eisenstrasse ambassadors can be rather located in the field of selected representation networks. Currently, the further development of the approach is still vague, but the regions problems such as demographic change are likely to play an important role. Thereby options to extend the approach in the form of youth ambassadors are considered. While the process of specifying the target groups is not yet finalised, necessary instruments for addressing potential target groups have already been explored.

The examples point out to the fact that ambassadors can indeed campaign for completely different things. This depends on the emphasis set by the respective region - in the examples; these are primarily of demographic (Waldviertel) or economic (Erzgebirge) nature. In order to link the adequate aspects to the selected target groups, it is necessary that the region has a precise notion of its own identity. Moreover, those responsible should be able to precisely define the target groups. Likewise, it becomes evident that the objective is directly oriented towards the problems faced by structurally weak, small town areas. The approach renders it 
possible to implement a network concerning the specific development needs of the areas (demographic development in the Waldviertel; economy in the Erzgebirge and image in the case of the Eisenstrasse). To some extent, these initiatives are capable of gaining a considerable momentum.

The aspect of determining the target groups - whose significance and complexity was markedly exemplified by the case studies - points towards the governance of such ambassador approaches. Here, it is required to formulate some requirements and tasks for the ambassadors so that they become aware of their role and will remain active throughout the process. In doing so, the case studies employ entirely different mechanisms: The Waldviertel region has ceded the realisation of the ambassador approach to a private agency per political mandate - which now coordinates a considerable amount of municipalities and ambassadors. In contrast, the German approach resorts to the governance by the administrative district. The case study Eisenstrasse currently utilises a semi-governmental approach that is organised largely by the LEADER management. The selected model of governance is also reflected by differing needs in coordinating the approaches. The complex management of an association composed of municipalities with a large pool of ambassadors requires other administrative preconditions (and political mandate) than a close-knit ambassador network with a limited number of participants. Referring to the latter case, the participants (as in the case of the Erzgebirge) might additionally also be attracted by the representative character of the network, as well as the district's direct patronage. The chosen instruments then differ depending on the orientation of the scheme: The ambassador meetings take place under different conditions in all the case studies. In the case of open networks, like the Waldviertel approach, the public image (for example via web platforms) plays an important role. Besides that, brochures and other information materials were also utilised. Hereto, the varying governance intensities become apparent which can, to some extent, significantly increase the organisational efforts (an annual conference with hundreds of participants versus a one-time information brochure).

Furthermore, the duties of the respective ambassadors in terms of their activities vary greatly. The main tasks of Eisenstrasse ambassadors (due to their personal relation to the region) is to publicise, help on and enhance the framework conditions of the region in all fields - economy, culture, tourism, education and media - and, thereby, overcome new challenges. Relating to that, practical liabilities are formulated for the ambassadors (networking, feedback to the region, participation in ambassador meetings, mentoring, sponsorship etc.). In the Waldviertel case, the primary task of the ambassadors is to carry further the region's strengths and report on the quality of living in the Waldviertel region first-hand. The marketing of the topic is supported by an internet platform featuring i.e., real estate offers. Additionally, every ambassador makes short, concise statements about the qualities of the Waldviertel. On the other hand, the duties of ambassadors according to the Erzgebirge approach, is to represent the region as a business location by referring to the achievements of their enterprises. This is achieved through advertisement campaigns, ambassador meetings and other exchange of information.

In the end, hardly any precise assertions can be made on the effects of the approaches in terms of regional development. This is due to the fact that none of the examples has performed a thorough evaluation yet. The Waldviertel case study, amongst others, refers to the amount of ambassadors, frequency of media reports, and number of visits to the website, social media, and studies on the acceptance as well as the general sentiment towards the ambassadors in the region. Statistical data used by the ambassador concept "Living in Waldviertel" also depict a positive net migration change in recent years as well as an increased in-migration from the destination area of Vienna. In addition, the mood in the region and the sentiment of the ambassadors (as it is perceived by the persons in charge) are stated as good indicators for the success of these measures.

Nevertheless all these named factors cannot be clearly attributed to the work of the network itself. Therefore direct impacts of such networks on regional development remain hard to assess, a fact that is even more valid in the case of exclusive networks, where the identification of success appears to be even more difficult. 


\section{Conclusion}

This paper has examined regional ambassador approaches in peripheral, small-town areas of Central Europe with the help of three selected case studies. The core issue of the analysis was what kind of possibilities and difficulties arise from the implementation of regional ambassador concepts. Ultimately, the paper at hand asked whether such approaches constitute an innovative and successful approach of regional development in small towns and what preconditions must be fulfilled for that.

The paper has shown that Austrian settlement patterns have been subject to continuous transformation processes since the 1990s. The trends in small towns are, in fact, spatially diverse. Especially peripheral, structurally weak areas are exposed to a range of economic, demographic and social pressures. Interestingly, ambassador concepts often articulate and examine exactly such specific regional development problems. With regard to the practical problems faced by small towns, these approaches offer the possibility to address topics such as demographic change actively and by including a broad set of regional stakeholders. Based on that, regions were able to develop a network and create marketing tools to create outside attention. Particularly, in the case of small-town areas which have already been subject to long downward trends, this result should not be underestimated. Ambassador approaches can also help foster local identification with the region and, ideally, also invigorate local pride. These positive effects might explain the increasing popularity of the ambassador approach across Central Europe.

The analysis pointed out that ambassador approaches are not implemented by individual municipalities or small towns but established on a regional level. This does reflect the organisational and coordination efforts necessary. In terms of Austria, this development also emphasises the fact that small towns are gradually integrated into larger contexts (in this case: city regions), especially as endogenous resources for action are generally decreasing in structurally weak areas. Here, the ambassador approach also allows for a better regional networking. This renders it possible to put the problems faced by peripheral small towns into a larger context within the city region. This could enhance options for action. Due to the fact that the costs are allotted to the region, the financial leeway for configuring such ambassador networks becomes larger.

A huge advantage of ambassador approaches is their cost-benefit ratio. In comparison to conventional marketing campaigns, the financial expenses of ambassador networks are limited to personnel costs for taking care of the network as well as accompanying marketing measures. This allows for a cost-effective PR-model with an intermediate to long-term process duration. This is also the precondition for the success of this approach in order to be able to achieve a sustainable improvement. Thus, it can be noted that ambassador approaches are not pure marketing elements. They also deal with interlinking the ambassadors' goals and the objectives of regional development representatives in these regions. This particularly applies to peripheral and structurally weak areas, as the case studies described in this paper have exemplified.

In conclusion, it can be asserted that ambassador approaches can have a range of positive impacts on regional development for small towns in structurally weak regions. These are namely the mobilisation of broad levels of the population, an enhanced identification and commitment, network and positive feedback effects on the economic as well as the social situation in the region. The interaction of a couple of measures is often a prerequisite for positive developments across the region. Because of that, ambassador concepts can be seen as a supporting measure in the time consuming processes of structural change, through which many small towns are going. For this reason, positive developments within an entire region cannot directly be attributed to the establishment of ambassador concepts.

The analysis, however, also revealed that these effects require a high degree of organisation which can be problematic especially in the case of structurally weak municipalities. Besides that, the unclear evaluation issue is one of the weak spots of all of the approaches discussed here. These aspects may be a particular hindrance for the allocation of long-term resources in financially and staff-wise limited municipalities. 
[1] Andersson, M. \& Ekman, P. (2009). Ambassador networks and place branding. Journal of Place Management and Development 2(1), 41-51. Doi: 10.1108/17538330910942799.

[2] Ashworth, G. \& Kavaratzis, M. (2007). Beyond the logo: Brand management for cities. Journal of Brand Management 16(8), 520-531. Doi:10.1057/palgrave.bm.2550133.

[3] Bähr, J. (2011). Einführung in die Urbanisierung. In On-line Handbuch Demographie. Berlin: Institut für Bevölkerung und Entwicklung Retrieved from: http://www.berlininstitut.org/fileadmin/user_upload/handbuch_texte/pdf_Baehr_Einfuehrung_Urbanisierung_ 2011.pdf.

[4] Baker, W. W. (2012). Destination branding for small cities: the essentials for successful place branding. Portland: Creative Leap Books.

[5] Collits, P. (2008). Small town decline and survival: trends, causes and policy issues. In: Rodgers, M., Collins, Y. M. J., eds., The Future of Australia's Country Towns. Melbourne: La Trobe University.

[6] Courtney, P. \& Errington, A. (2000). The Role of Small Towns in the Local Economy and Some Implications for Development Policy. Local Economy 15(4), 280-301. Doi: 10.1080/026909400750068013.

[7] Dinnie, K. (2011). City Branding: Theory and Cases. Basingstoke: Palgrave Macmillan.

[8] Erickcek, G. A. \& McKinney, H. J. (2006). Small Cities Blues: Looking for Growth Factors in Small and Medium-Sized Cities. Economic Development Quarterly 20(3), 232-258. Doi: $10.1177 / 0891242406290377$.

[9] Fischer, W., Harfst, J. \& Simic, D. (2016). Exkursion zur Steirischen Eisenstrasse. (Teil 1: Von Trofaiach auf den Präbichl). Grazer Mitteilungen der Geographie und Raumforschung 59, 44-50.

[10] Giffinger, R. \& Kramar, H. (2012). Kleinstädte als Wachstumsmotoren ländlich-peripherer $\begin{array}{lllll}\text { Regionen: Das } \quad \text { Beispiel } & \text { Waldviertel. }\end{array}$ Doi: 10.1080/02513625.2012.721609.

[11] Giffinger, R. \& Kramar, H. (2008). Schrumpfung und Erosion im österreichischen Siedlungssystem: strukturelle Kennzeichen und regionale Perspektiven. In Erosionsprozesse im Siedlungsgefüge Österreichs (pp.9-28). Wien/Berlin: LIT Verlag.

[12] Go, F. M. \& Govers, R. (2010). International place branding yearbook 2010: place branding in the new age of innovation. Basingstoke: Palgrave Macmillan.

[13] Govers, R. \& Go, F. (2009). Place Branding: Glocal, Virtual and Physical Identities, Constructed, Imagined and Experienced. Basingstoke: Palgrave Macmillan.

[14] Harfst, J. \& Wirth, P. (2014). Zur Bedeutung endogener Potenziale in klein- und mittelstädtisch geprägten Regionen - Überlegungen vor dem Hintergrund der Territorialen Agenda 2020. Raumforschung und Raumordnung 72(6), 463-475. Doi:10.1007/s13147014-0312-9.

[15] Knox, P. \& Mayer, H. (2013). Small Town Sustainability: Economic, Social, and Environmental Innovation. $2^{\text {nd }}$ Edition. Basel/Boston/Berlin: Birkhäuser.

[16] Kwiatek-Soltys, A., Mainet, H., Wiedermann, K. \& Edouard, J.-C. (Eds.) (2014). Small and Medium Towns' Attractiveness at the beginning of the $21^{\text {st }}$ Century. Clermont-Ferrand: Presse Universitaires Blaise Pascal.

[17] Leeuwen van, E. (2010). Urban-Rural Interactions - Towns as Focus Points in Rural Development, Contributions to Economics. Heidelberg: Physica.

[18] Moinat, V. R. \& Diesbach, P. L. (2009). Rejuvenating Touristic Consumption: From a Cognitive Approach to a Symbolic Intent of Modelisation. In Fyall, A., Kozak, M., Andreu, 
L., Gnoth, J. \& Lebe, S. S., eds., Marketing Innovations for Sustainable Destinations (pp. 54-65). Oxford: Goodfellow Publishing.

[19] Pichler, P. (2015). Botschaftermodelle als Instrument der Regionalentwicklung - am Beispiel der „Steirischen Eisenstrasse“ [Master thesis]. University Graz.

[20] Rehmet, J. \& Dinnie, K. (2013). Citizen brand ambassadors: Motivations and perceived effects. Journal of Destination Marketing and Management. 2(1), 31-38. Doi: 10.1016/j.jdmm.2013.02.001.

[21] Schnaitl, C. (2012). Öffentlicher Leerstand in strukturschwachen Gemeinden - was tun? [Master thesis]. Wien: Universität für Bodenkultur.

[22] Servillo, L., ed. (2014). TOWN - Small and medium sized towns in their functional territorial context [Research Report]. Luxembourg: ESPON Coordination Unit.

[23] Silverman, G. (2011). The Secrets of word-of-mouth marketing how to trigger exponential sales through runaway word of mouth. New York: American Management Association.

[24] Vaishar, A. \& Zapletalová, J. (2009). Small towns as centres of rural micro-regions. European Countryside 1(2), 70-81. Doi: 10.2478/v10091-009-0006-4.

Other sources

[25] Österreichischen Raumordnungskonferenz (ÖROK) (Ed.), (2015). Für eine österreichische Stadtregionspolitik Agenda Stadtregionen in Österreich Empfehlungen der ÖREKPartnerschaft „Kooperationsplattform Stadtregion“.

[26] Österreichischen Raumordnungskonferenz (ÖROK) (Ed.), (2009). Räumliche Entwicklungen in österreichischen Stadtregionen: Handlungsbedarf und Steuerungsmöglichkeiten. Österreichische Raumordnungskonferenz. 